\title{
Valorization of apple tree wood residues by polyphenols extraction: Comparison between conventional and microwave- assisted extraction
}

\author{
Manuela M.Moreira \\ M. Fátima Barroso \\ Annick Boeykens \\ Hannes Withouck \\ Simone Morais \\ Cristina Delerue-Matos
}

\section{Abstract}

For the first time, the characterization of antioxidant activity and phenolic profile of apple tree (Malus domestica) bark, core and roots was carried out. Phenolic compounds were extracted from the Belgium apple tree wood residues collected at two seasons, namely summer 2015 and winter 2016, using conventional (CE) and microwave-assisted extraction (MAE) techniques. For each extraction technique, the influence of the most important operational parameters, namely solvent composition, extraction time and temperature, on the total phenolic and flavonoid content, and antioxidant activity by the 2,2-diphenyl-1-picrylhydrazyl radical scavenging activity (DPPH-RSA) and ferric reducing activity power (FRAP) assays were optimized. The phenolic profile from the obtained extracts was also characterized by high-performance liquid chromatography with photodiode array detection (HPLC-PDA). Optimum conditions were: $20 \mathrm{~mL}$ ethanol:water 60:40 v/v, $20 \mathrm{~min}, 100{ }^{\circ} \mathrm{C}$, sample weight $0.1 \mathrm{~g}$ for MAE and $20 \mathrm{~mL}$ ethanol:water $50: 50 \mathrm{v} / \mathrm{v}, 2 \mathrm{~h}, 55^{\circ} \mathrm{C}$, sample weight $0.5 \mathrm{~g}$ for CE. Root extracts obtained by MAE (the most efficient technique) presented the highest phenolic (47.7 \pm $0.9 \mathrm{mg}$ gallic acid equivalents $/ \mathrm{g}$ dry weight) and flavonoid (17.1 $\pm 0.8 \mathrm{mg}$ epicatechin equivalents $/ \mathrm{g}$ dry weight) content, and antioxidant activity (28.4 $\pm 2.0 \mathrm{mg}$ trolox equivalents/g dry weight and 36.1 $\pm 2.7 \mathrm{mg}$ ascorbic acid equivalents/g dry weight for DPPH-RSA and FRAP assays, respectively), followed by bark and core wood extracts. HPLC-PDA analysis revealed that phloridzin was the main contributor to the phenolic composition representing $52 \%-87 \%$ of the total amount of phenolic compounds quantified, while phenolic acids represents less than $10 \%$. This study reveals the potential of apple tree wood residues valorization through the recovery of phenolic compounds for food, pharmaceutical and cosmetic applications. 


\section{Keywords}

Apple tree wood; Microwave-assisted extraction; Conventional extraction; Antioxidant activity; Phenolic compounds; HPLC analysis

\section{Introduction}

Polyphenols are one of the main groups of secondary plant metabolites, essentially for their normal growth and defense against infection and injury, and their health benefits have been extensively described (El Gharras, 2009, Ghitescu et al., 2015, Stevanovic et al., 2009). In the last few years, search of inexpensive and renewable sources of polyphenols has been attracting researchers interest. For that reason, the number of publications concerning the extraction of these compounds from biomass has been increasing (Bouras et al., 2015, Ghitescu et al., 2015, Hofmann et al., 2015, Lazar et al., 2016).

Every year, Belgium apple farmers renew $6 \%$ of the apple plantation, which reflects in the annual production of 30,000 ton of woods residues (FAOSTAT, 2015). Traditionally, these apple tree residues are used in low added value applications, such as firewood or dispersed (Dedrie et al., 2015, Ghitescu et al., 2015). Still, in last few years, tree materials, such as bark, have been emerging as possible sources of valuable compounds (Table 1) (Ghitescu et al., 2015, Hofmann et al., 2015). To this regard, the recovery of phenolic compounds from these wood wastes is gaining considerable attention, especially ascribable to the antioxidant properties that these compounds exert (Kammerer et al., 2014, Stevanovic et al., 2009). 
Table 1

\begin{tabular}{|c|c|c|c|c|}
\hline sanple & Exeraction technique and coedisbens & TPC: & TPC uniks & Reternoce \\
\hline 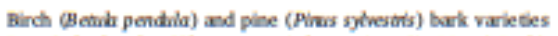 & sinting $500 \mathrm{mg}, 2 \times 10 \mathrm{~mL}$ of mentanotwater $50,20 \mathrm{v} / \mathrm{k}, 1 \mathrm{~min}$ & $20 \pm 0.1-760 \pm 29$ & $\mathrm{mg} \mathrm{GAE}^{\mathrm{b}} / \mathrm{g} \mathrm{DW}^{\mathrm{c}}$ & Kahbonen et al (1999) \\
\hline 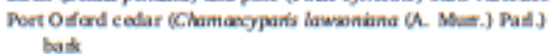 & SE." $100 \mathrm{~g}, 1 \mathrm{~L}$ of metasol & $777-88.8$ & $=g$ GAE/g DW & Gas et al $(2007)$ \\
\hline 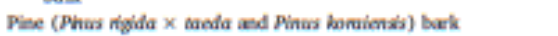 & $10 \mathrm{~g}, 100$ mL, bolling wres, 1 | & $111-862$ & $=\mathrm{m}_{\mathrm{C}} \mathrm{CE} / \mathrm{g}$ extract & Na es at. (20007) \\
\hline Bark of Phollantess envika L. & MAE $3 \mathrm{z} 75 \%$ aqpeose etheol, $25 \mathrm{~min}, 45^{\prime} \mathrm{C}$ & 198 & & Yang ef al (0009) \\
\hline 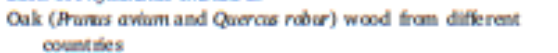 & $500 \mathrm{mg}$ of sawdist, $30 \mathrm{~mL}$, methreol, $30 \mathrm{~min}, \mathrm{RT}$ & $\begin{array}{l}6.9 \pm 0.37- \\
1012 \pm 1.2\end{array}$ & $\underset{\text { wood }}{\mu \mathrm{GAE} / \mathrm{g} \text { odk }}$ & Nade et al (2011) \\
\hline \multirow[t]{4}{*}{ Pinas radatax balk } & 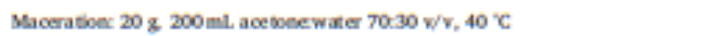 & $412 \pm 0$ & 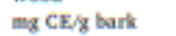 & Aped and Fenshoder (2011) \\
\hline & 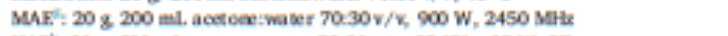 & $479 \pm 49$ & & \\
\hline & 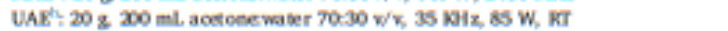 & $306 \pm 7$ & & \\
\hline & 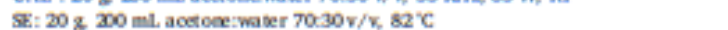 & $622 \pm 40$ & & \\
\hline Pines radotara bark & 1003, 2 L ethasodwer $3: 1 \mathrm{w} / \mathrm{w}, 120 \mathrm{~min}, 120^{\circ} \mathrm{C}$ & $0.55 \pm 0.01$ & g GAE/z extrat & Bocaledro et al (2012) \\
\hline Bark of Mactra tinctaria (L) & sinfing aceboecwae $70.30 \times \mathrm{N}, 30 \mathrm{~min}, \mathrm{RT}+10 \mathrm{~min}$ at $85^{\circ} \mathrm{C}$ & $43.2 \pm 1.2$ & mgat $\mathrm{GA} / \mathrm{g}$ & Lanovender of a (2012) \\
\hline \multirow[t]{3}{*}{ 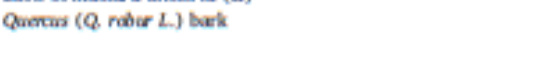 } & Maceraboes $5 \mathrm{~g}, 100 \mathrm{mal}$, wase, $120 \mathrm{~min}, 25 \mathrm{c}$ & $3.7 \pm 0.6$ & $=g$ GAE/g bark & Bowras et al. (2015) \\
\hline & Heat xelax: $5 \mathrm{~g}, 100 \mathrm{~mL}$ water, $120 \mathrm{~min}, 100^{\circ} \mathrm{C}$ & $117 \pm 0.5$ & & \\
\hline & MAE 5 g $100 \mathrm{me}$, wae, $120 \mathrm{~min}, 100 \mathrm{k}, 400 \mathrm{~W}$ & $1650 \pm 0.7$ & & \\
\hline \multirow[t]{4}{*}{ Fresch maritime pine bask (Pines pinuxen) } & Maceraboe $1 \mathrm{~g} .9 \mathrm{~mL}$ d w waser $+16 \mathrm{NaOH}+0.25 \% \mathrm{Na}_{2} \mathrm{SO}_{3}+0.25 \%$ NarsO & $542 \pm 19.4$ & $m g$ GAR/g burk & Ompin ef al. (e015) \\
\hline & 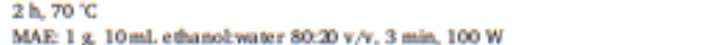 & $283 \pm 29$ & & \\
\hline & 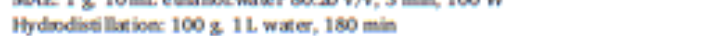 & $143 \times 20$ & & Mol bakk et al. (2015) \\
\hline & Solven tree MNE: $1008.924 \min 800.5 \mathrm{~W}$ & 1302 & & \\
\hline Oak bark Quences rober L and Queras perions & 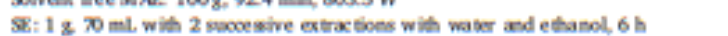 & $50 \pm 0.3-134 \pm 0.2$ & $m g A R / z$ IW & Dodrie ef al. (2015) \\
\hline \multirow[t]{3}{*}{ Bark of Solidioge candents $\mathrm{L} z$} & 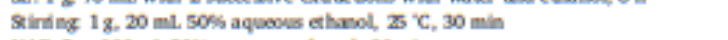 & $0.001 \pm 0.011-1.384 \pm 0.020$ & $=g \mathrm{GAE} / \mathrm{g}$ & Deng et al (2015) \\
\hline & UAE 5 \& $100 \mathrm{ml}, 50 \%$ aquowe etasd, 30 ma & & & \\
\hline & 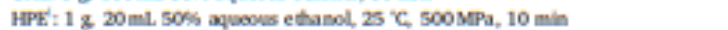 & & & \\
\hline Spesce bark & 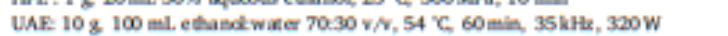 & 13.2 & $=\mathrm{mgAF} / \mathrm{g}$ & Ghineruet al (2015) \\
\hline \multirow[t]{3}{*}{ Beech bark (Fogsis githatica L) } & 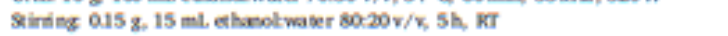 & $48.3 \pm 1.2$ & $=\mathrm{QE} / \mathrm{g} \mathrm{DW}$ & Hodmann ef al (2019) \\
\hline & 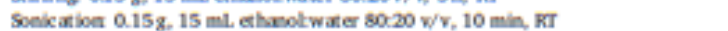 & $49.9 \pm 1.1$ & & \\
\hline & MAE Q15 \& $15 \mathrm{ml}$, edand waser $30.20 \mathrm{r} / \mathrm{r}, 20 \mathrm{~min}, 120^{\circ} \mathrm{C}$ & $65.2 \pm 5.6$ & & \\
\hline \multirow[t]{5}{*}{ Mowcan Acada nowisima bark } & Stinting $10 \mathrm{~g}, 20 \mathrm{~mL}$, wethrootwater $80,20 \mathrm{~W} / \mathrm{k}, 2 \mathrm{~h}, 20^{\circ} \mathrm{C}$ & $3536 \pm 0.5$ & $m g$ GAE/g turk & Naima e al (2015) \\
\hline & 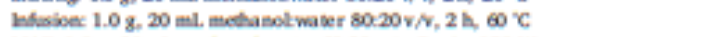 & $2584 \pm 3.6$ & & \\
\hline & MAE $1.0 \mathrm{z} 20 \mathrm{ml}$, methand waser $80.20 \mathrm{v} / \mathrm{\gamma}, \mathrm{s} \min .150 \mathrm{~W}$ & $4416 \pm 0.3$ & & \\
\hline & MAE $1.0 \mathrm{~g} 20 \mathrm{~m}$, ethasd, $5 \mathrm{~min}, 150 \mathrm{~W}$ & $2727 \pm 8.1$ & & \\
\hline & MAE $1.0 \mathrm{~g} 20 \mathrm{~mL}$ wore, $5 \mathrm{~min}, 150 \mathrm{~W}$ & $2988 \pm 0.6$ & & \\
\hline Spasce bark (Picen abies) & UAE: 5 \& $50 \mathrm{ml}$, etand water $7030 \mathrm{v} / \mathrm{v}, 60 \mathrm{c}, 35 \mathrm{kHz}, 320 \mathrm{~W}$ & 431.100 & $m g$ GAE $/ g$ & Lavar et al (2016) \\
\hline
\end{tabular}

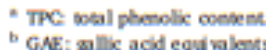

'DW: dry neighe

d $\mathbf{E}$ : Sorblet extraction.

- CE: easechitim equitivienos.

( $\mathrm{kT}$ : nom temperature.

MAE micromave assisted extration.

UAE whrasoned asisted extraction.

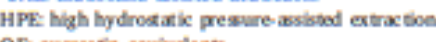

QE queroetin equinitems. 
The extraction technique applied in polyphenols recovery is the key step for a high-yield and efficient process. Despite of conventional extraction (CE) techniques, such as maceration and Soxhlet extraction (SE), still being widely used, there is an increasing demand for more sustainable extraction methods. In recent years, new green extraction techniques, such as ultrasound-assisted extraction (UAE) and microwave-assisted extraction (MAE), have been developed and used for the extraction of phenolic compounds from tree woods (Aspé and Fernández, 2011, Khoddami et al., 2013). Regarding polyphenols extraction from apple tree woods, only one report for phloretin extraction was published until now. Xü et al. (2010) separated and purify phloretin from Fuji apple tree bark by high-speed countercurrent chromatography (HSCCC) on a preparative scale. Phloretin was extracted by reflux with ethanol as extracting solvent, and $39.2 \mathrm{mg}$ (98.2\% purity) of phloretin was obtained from $767.3 \mathrm{mg}$ of the crude phloretin extract. This lack of information on phenolic composition characterization from apple tree wood residues represents an interesting research area to create a more profitable valorization of these residues.

The principal aim of the present work was the phenolic and antioxidant characterization of Malus domestica 'King Jonagold' bark, core and roots collected at two different seasons, namely in summer and winter. To achieve this goal, CE and MAE were carried out. The most important parameters in each extraction technique were optimized. Extraction efficiency of both techniques was evaluated by the total phenolic content (TPC) and total flavonoid content (TFC), as well as by the antioxidant activity assays, namely, 2,2-diphenyl-1-picrylhydrazyl radical scavenging activity (DPPH-RSA) and ferric reducing activity power (FRAP). Moreover, characterization of phenolic composition from apple tree bark, core and roots by high-performance liquid chromatography with photodiode array detection (HPLC-PDA) was also carried out to see which individual phenolic compound is contributing the most to the antioxidant properties of the produced extracts.

\section{Materials and methods}

\subsection{Chemicals and reagents}

Gallic acid (GA, $\geq 98 \%$ ), trolox (6-hydroxy-2,5,7,8-tetramethylchroman-2-carboxilic acid, 98\%) and (-)epicatechin $(\geq 97 \%)$ standards were obtained from Sigma-Aldrich (Madrid, Spain). Other products purchased from Sigma-Aldrich or Fluka were: Folin-Ciocalteu reagent, sodium-carbonate ( $\geq 99 \%)$, DPPH reagent, TPTZ (2,4,6-Tris(2-pyridyl)-s-triazine, 99\%) and aluminum chloride hexahydrate (99\%). Ascorbic Acid (AA, 99.7\%) was purchased from Riedel-de Haën and sodium nitrite ( $\geq 97 \%)$ from Merck. Ethanol absolute anhydrous (p.a.) was bought from Carlo Erba (Peypin, France), methanol and formic acid (HPLC grade) were obtained from Merck (Darmstadt, Germany), and ultrapure water $(18.2 \mathrm{M} \Omega \mathrm{cm}$; Simplicity 185 apparatus; Millipore, Molsheim, France) was used during the experiments. 
For HPLC analysis reference standards of phenolic compounds purchased from Sigma-Aldrich (Steinheim, Germany) were used in this study, namely the phenolic acids: protocatechuic acid (99.63\%), vanillic acid ( $\geq 97 \%)$, syringic acid ( $\geq 98 \%)$, $\beta$-resorcylic acid ( $\geq 97 \%)$, 4-hydroxybenzoic acid $(\geq 99 \%)$, 4hydroxybenzaldehyde (98\%), ferulic acid ( $\geq 99 \%)$, sinapic acid $(\geq 99 \%)$, cinnamic acid ( $\geq 99 \%)$, caffeic acid $(\geq 98 \%)$, p-coumaric acid ( $\geq 98 \%)$, chlorogenic acid (>95\%), 4-hydroxyphenylacetic acid (98\%); flavonoids: $(+)$-catechin $(\geq 98 \%)$, naringin $(\geq 95 \%)$, naringenin $(98 \%)$, rutin hydrate $(\geq 94 \%)$, quercetin $(95 \%)$, kaempferol $(\geq 98 \%)$, myricetin $(\geq 96 \%)$, pinocembrin $(95 \%)$, tiliroside ( $\geq 98 \%)$, quercetin-3-Oglucopyranoside ( $\geq 99 \%)$, kaempferol-3-O-rutinoside ( $\geq 98 \%)$, kaempferol-3-O-glucoside ( $\geq 95 \%)$; tiliroside $(\geq 98 \%)$; chalcones: phloridzin dehydrate $(99 \%)$ and phloretin $(\geq 98.5 \%)$; and the stilbenoid resveratrol $(\geq 99 \%)$. Individual stock solutions of the above polyphenols were prepared in methanol at concentrations ranging from 1 to $5 \mathrm{~g} / \mathrm{L}$ and stored at $-20{ }^{\circ} \mathrm{C}$.

\subsection{Sample preparation}

Apple tree wood (Malus domestica 'King Jonagold') was collected during September of 2015 and February 2016 in Herk-de-Stad, Belgium. Bark, core and roots were separated and dried first at $50{ }^{\circ} \mathrm{C}$ for $22 \mathrm{~h}$, followed by $4 \mathrm{~h}$ drying at $103^{\circ} \mathrm{C}$. Moisture content was measured using a Moisture Analyser (Kern MLS 50-3IR160) until a constant weight of the sample was attained. The moisture content ranged from $10.1 \pm 0.4$ to $15.2 \pm 0.8 \%$. After drying, apple tree woods were ground in a mill (Retsch ZM200) and sieved to select particles smaller than $0.08 \mathrm{~mm}$. The ground bark, core and roots were kept in sealed bags at room temperature. All analytical results were presented per dry weight of sample (DW).

\subsection{Extraction procedures}

\subsubsection{Microwave-assisted extraction}

MAE was performed with a MARS-X 1500 W (Microwave Accelerated Reaction System for Extraction and Digestion, CEM, Mathews, NC, USA) using 14 Teflon extraction vessels.

In a first stage, some preliminary assays were performed in order to analyze the influence of extraction solvent (water, methanol and ethanol, and mixtures of these solvents in several proportions), temperature $\left(60,100\right.$ and $\left.120^{\circ} \mathrm{C}\right)$, and mass/solvent ratio $(0.1 / 20,0.5 / 20$ and 1.0/20, w/v) on the amount of phenolic compounds recovered from bark and core collected at 2015. In a second stage, based on the previous results, MAE optimization was planned according to a 23 factorial experimental design (Table 2) as described in Section 2.7. After centrifugation (Heraeus ${ }^{\mathrm{TM}}$ Megafuge $^{\mathrm{TM}} 16 \mathrm{R}$ Centrifuge, Thermo Scientific) at $4000 \mathrm{rpm}$ for $10 \mathrm{~min}$, MAE wood extracts were collected and stored in the freezer at $-20{ }^{\circ} \mathrm{C}$ until further analysis. 
Table 2. Real values and coded levels for the experimental design $2^{3}\left(\mathrm{X}_{1}-\right.$ extraction time; $\mathrm{X}_{2}$ - sample weight; $\mathrm{X}_{3}$ - temperature), experimental results (mean of four replicates for each run) and predicted values for the total phenolic content (mean \pm standard deviation, $n=3$ ). Conditions: $20 \mathrm{~mL}$ of ethanol:water $(60: 40$; $\mathrm{v} / \mathrm{v})$ and medium stirring speed.

\begin{tabular}{|c|c|c|c|c|c|}
\hline Run & $\begin{array}{l}\text { Extraction time } \\
\left(\mathrm{X}_{1}, \mathrm{~min}\right)\end{array}$ & $\begin{array}{l}\text { Sample weight }\left(\mathrm{X}_{2},\right. \\
\left.\mathrm{g} \mathrm{DW}^{2}\right)\end{array}$ & $\begin{array}{l}\text { Temperature } \\
\left(\mathrm{x}_{3,}{ }^{\circ} \mathrm{C}\right)\end{array}$ & $(\mathrm{mg} \mathrm{GAE} / \mathrm{g} \mathrm{DW})^{c}$ & $\mathrm{TPC}_{\text {predicted }} \pm \mathrm{SD}$ \\
\hline 1 & $(-1) 10$ & $(-1) 0.25$ & $(-1) 80$ & $31.0 \pm 1.1$ & $30.3 \pm 1.1$ \\
\hline 2 & (1) 30 & $(-1) 0.25$ & $(-1) 80$ & $32.4 \pm 1.6$ & $32.9 \pm 1.6$ \\
\hline 3 & $(-1) 10$ & (1) 0.75 & $(-1) 80$ & $27.2 \pm 0.3$ & $26.4 \pm 0.3$ \\
\hline 4 & (1) 30 & (1) 0.75 & $(-1) 80$ & $31.0 \pm 3.4$ & $30.6 \pm 3.4$ \\
\hline 5 & $(-1) 10$ & $(-1) 0.25$ & (1) 120 & $37.0 \pm 2.9$ & $37.4 \pm 2.9$ \\
\hline 6 & (1) 30 & $(-1) 0.25$ & (1) 120 & $36.5 \pm 2.5$ & $37.2 \pm 2.5$ \\
\hline 7 & $(-1) 10$ & (1) 0.75 & (1) 120 & $31.4 \pm 0.4$ & $30.9 \pm 0.4$ \\
\hline 8 & (1) 30 & (1) 0.75 & (1) 120 & $31.6 \pm 2.3$ & $32.3 \pm 2.4$ \\
\hline 9 & $(-1.682) 3$ & (o) 0.50 & (o) 100 & $27.0 \pm 1.0$ & $27.9 \pm 1.0$ \\
\hline 10 & $(1.682) 37$ & (0) 0.50 & (0) 100 & $32.2 \pm 3.0$ & $31.2 \pm 2.9$ \\
\hline 11 & (o) 20 & $(-1.682) 0.0795$ & (0) 100 & $39.6 \pm 0.7$ & $39.0 \pm 0.7$ \\
\hline 12 & (0) 20 & $(1.682) 0.9205$ & (0) 100 & $31.2 \pm 2.3$ & $31.7 \pm 2.3$ \\
\hline 13 & (0) 20 & (0) 0.50 & $(-1.682) 66$ & $27.1 \pm 1.1$ & $27.9 \pm 1.1$ \\
\hline 14 & (0) 20 & (o) 0.50 & $(1.682) 134$ & $36.2 \pm 3.4$ & $35.3 \pm 3.3$ \\
\hline 15 & (0) 20 & (o) 0.50 & (0) 100 & $28.5 \pm 0.3$ & $30.6 \pm 0.3$ \\
\hline 16 & (0) 20 & (0) 0.50 & (0) 100 & $32.0 \pm 0.1$ & $30.6 \pm 0.1$ \\
\hline 17 & (0) 20 & (o) 0.50 & (0) 100 & $30.8 \pm 0.3$ & $30.6 \pm 0.3$ \\
\hline 18 & (0) 20 & (0) 0.50 & (0) 100 & $31.0 \pm 0.4$ & $30.6 \pm 0.4$ \\
\hline
\end{tabular}

a.

DW: dry weight.

$\mathrm{b}$

TPC: total phenolic content.

mg GAE/g DW: mg gallic acid equivalents/g dry weight of sample. 


\subsubsection{Conventional extraction}

CE optimization was carried out using $0.5 \mathrm{~g}$ of bark sample (collected at 2015) and $20.0 \mathrm{~mL}$ of solvent in glass Erlenmeyer flasks (protected with plastic paraffin film to prevent solvent evaporation and covered with aluminum foil to preserve phenolic compounds against reactions with light) placed in a water bath shaker (model BSC127E, C from OVAN) at 100 rpm. The parameters studied were the solvent composition $(1: 4,1: 1,4: 1 \mathrm{v} / \mathrm{v}$; ethanol:water), extraction time $(2,6$ and $24 \mathrm{~h})$ and temperature $\left(20\right.$ and $\left.55^{\circ} \mathrm{C}\right)$, and their range was defined taking into consideration our previous results from MAE and the results reported by Hofmann et al. (2015). Extracts were centrifuged at $4000 \mathrm{rpm}$ for $10 \mathrm{~min}$ and stored in the freezer at $-20^{\circ} \mathrm{C}$ until further TPC analysis.

\subsection{Total phenolic and flavonoid content}

TPC was measured using the Folin-Ciocalteau method (Paz et al., 2015) using GA as the standard, and the absorbance was measured at $765 \mathrm{~nm}$ in a microplate reader (black 96well plates, Nunc ${ }^{\text {TM }}$ black microwell, Denmark) after 90 min. Results were expressed as $\mathrm{mg}$ of GA equivalents per $g$ of dry weight of sample (mg GAE/g DW).

TFC was determined by the aluminum chloride method described in detail by Paz et al. (2015). (-)-Epicatechin was used as standard, and the results were expressed as $\mathrm{mg}$ of epicatechin equivalents per $\mathrm{g}$ dry weight of sample (mg EE/g DW). All measurements were performed in triplicate.

\subsection{Antioxidant capacity}

FRAP assay was performed according to the procedure developed by Paz et al. (2015) in a microplate reader at $593 \mathrm{~nm}$ at $37^{\circ} \mathrm{C}$. The calculations were made using a standard curve of $A A$, and the results were expressed as mg $A A$ equivalents per $g$ dry weight of sample (mg AAE/g DW). 
The free radical-scavenging activity of the extracts was determined spectrophotometrically using the stable radical DPPH following the procedure described before (Paz et al., 2015). A trolox standard was used to make the calibration curve and the results were expressed in mg trolox equivalents per $g$ dry weight of sample (mg TE/g DW). All the analyses were performed in triplicate.

\subsection{High performance liquid chromatography analysis of phenolic profile}

A Shimadzu HPLC system equipped with a LC-20AD prominence pump, a DGU-20AS prominence degasser, a CTO-10AS VP column oven, a SIL-20A HT prominence autosampler, and a SPD-M20A photodiode array detector (Kyoto, Japan) was used to analyze the apple wood extracts according to Carvalho et al. (2016) and Rubilar et al. (2007). A Phenomenex Gemini C18 column ( $250 \mathrm{~mm} \times 4.6 \mathrm{~mm}, 5 \mu \mathrm{m})$ and a guard column with the same characteristics maintained at $25^{\circ} \mathrm{C}$ with a gradient program were used for the separation of phenolic compounds. Mobile phase A (methanol) and mobile phase $B$ (water) both with $0.1 \%$ formic acid were used for elution at a flow rate of $1.0 \mathrm{~mL} / \mathrm{min}$. The following gradient was applied: 0-13 min: $20-26.5 \% A ; 13-18 \mathrm{~min}: 26.5 \% \mathrm{~A} ; 18-25 \mathrm{~min}$ : 26.5-30\% A; 25-50 min: 30-45\%A; 50-60 min: 45-50\%A; 60-70 min: 50-55\% A; 70-90 min: $55-70 \%$ A; $90-100 \mathrm{~min}: 70-100 \%$ A, followed by $100 \%$ for 5 min and back to $20 \% A$ in $10 \mathrm{~min}$ and $5 \mathrm{~min}$ of reconditioning before the next injection. The identification and quantification of the phenolic compounds in apple wood extracts was carried out by the comparison of the retention time and UV-vis spectra of detected peaks with those obtained for their pure standards. UV spectra was recorded in a range of 190-600 nm, and the quantification was made at 280,320 and $360 \mathrm{~nm}$ depending of the maximum absorption from the phenolic compound. Before injection, apple tree extracts were filtered through a $0.2 \mu \mathrm{m}$ PTFE syringe filter. Calibration curves from the previously mentioned standards in the concentration range of $1-200 \mathrm{mg} / \mathrm{L}$, prepared in a mixture of methanol-water (50:50, $\mathrm{v} / \mathrm{v}$ ) by dilution of appropriate amounts of the stock solutions, were obtained. Relevant analytical data, namely limit of detection (LOD) and quantification (LOQ), intra and inter-day method precision, are shown in Table 1S (Supplementary material). For the apple wood extracts, the concentrations were calculated based on triplicate injections and the results were expressed as $\mathrm{mg} / 100 \mathrm{~g}$ of DW of sample. 


\subsection{Experimental design}

Response surface methodology (RSM) coupled to a 23 full-factorial central composite design was employed to analyze the influence of MAE variables on the extraction of phenolic compounds from apple wood bark. Extraction time (X1, min.), sample weight (X2, g) and extraction temperature $\left(\mathrm{X} 3,{ }^{\circ} \mathrm{C}\right)$ were chosen as independent variables, and their effect on polyphenols yield was evaluated by the TPC. The complete design consisted of 18 experiments, including 4 runs of the central point and two axial points on the axis of each variable at a distance of $\alpha=1.682$ from the center. Coded and real values of the MAE variables and their ranges of variation, which were defined taking into consideration the results from preliminary tests, are listed in Table 2.

The relationship between the extraction yield and the independent variables were fitted with a second-order response surface model expressed in Eq. (1) (Montgomery, 1991):

$$
Y=\beta_{0}+\sum_{j=1}^{k} \beta_{j} X_{j}+\sum_{j=1}^{k} \beta_{i j} X_{j}^{2}+\sum \sum_{i<j} \beta_{i j} X_{i} X_{j}+\varepsilon
$$

where $Y$ is the experimental response (expressed as TPC), $\beta 0, \beta \mathrm{j}, \beta \mathrm{jj}$, $\beta \mathrm{ij}$ are the constant coefficients of interception, linear, quadratic, and interaction terms, respectively; $\mathrm{Xì} \mathrm{and} \mathrm{Xj}$ are the coded independent variables, and $\varepsilon$ is the experimental error. Statistical analysis and response surface 3D plots (generated by using the function of two factors, and keeping the other constant) were performed with Statistica (v. 7, StatSoft Inc., USA) and used to evaluate the interaction among the independent variables and their effect on the polyphenols yield.

\subsection{Statistical analysis}

All the assays were conducted in triplicate and the results were expressed as mean \pm standard deviation (SD). The comparison of the results was made by the software SPSS (IBM SPSS Statistics 20) applying the nonparametric Mann-Whitney $U$ test at the significance level of $p \leq 0.05$. 


\section{Results and discussion}

\subsection{Preliminary assays}

Taking in consideration our previous knowledge in MAE (Mendes et al., 2016, Moreira et al., 2012, Paíga et al., 2013), some preliminary experiments were carried out in order to choose the relevant variables and their experimental range in phenolic compounds recovery from apple tree woods. TPC of the obtained extracts was used to evaluate the effect of each variable.

One of the most important and investigated parameters in polyphenols extraction efficiency is the solvent composition. Tree woods are composed by different compounds with varied chemical characteristics and polarities which requires the selection of a suitable solvent (Bouras et al., 2015, Ghitescu et al., 2015, Muñiz-Márquez et al., 2013, Naima et al., 2015). Different pure solvents, i.e. water, methanol and ethanol, and mixtures of these solvents in several ratios were tested using a sample weight of $0.50 \mathrm{~g}$ and a solvent volume of $20 \mathrm{~mL}$ at $100{ }^{\circ} \mathrm{C}$ during $15 \mathrm{~min}$ with medium stirring. Table 3 shows the impact of solvent choice in TPC of bark and core (from samples collected during 2015). For both samples, it was observed that a mixture of organic solvent and water is more efficient in extracting phenolic compounds than pure solvents (Bouras et al., 2015, Lazar et al., 2016) and that, whatever the type of alcohol used, the trend of the results was similar. The highest TPC was obtained using mixtures of solvents with concentrations of $60 \%$ and $80 \%$ of organic solvent in water, with no significant differences between both compositions. Recent investigations in matrices similar to apple tree woods are in agreement with these results, where the yield of phenolic compounds was improved till $80 \%$ of ethanol or methanol (Ghitescu et al., 2015, Hofmann et al., 2015, Lazar et al., 2016, Naima et al., 2015). This phenomenon can be attributed to the properties of both solvents, where water is altering the sample structure acting as a swelling agent enabling the solvent to easily penetrate inside bark and core, while the organic solvent is disrupting the bonding between the solutes and sample (Bouras et al., 2015, Ghitescu et al., 2015, Muñiz-Márquez et al., 2013). Another explanation for the obtained results can be associated to the high dielectric constant of water, which is a very important parameter in MAE (Morais, 2013). The efficiency and selectivity of MAE strongly depend from the dielectric constant of the solvent mixture; therefore, the addition of water 
increases the polarity indices of organic solvents, which reflects in an easier absorption of microwave energy increasing the temperature inside the sample leading to the rupture of cells and an easier release of phenolic compounds (Bouras et al., 2015, Chan et al., 2011, Drosou et al., 2015, Morais, 2013).

Table 3. Evaluation of microwave-assisted extraction solvent effect on the total phenolic content (mean \pm standard deviation, $n=3$ ) of bark and core samples collected during 2015. Other operational conditions: $20 \mathrm{~mL}$ of solvent, $0.5 \mathrm{~g}$ sample, $100^{\circ} \mathrm{C}, 15 \mathrm{~min}$ and medium stirring speed.

\section{Solvent Composition}

(v/v)

Water

Methanol:water (20:80)

Methanol:water (40:60)

Methanol:water (60:40)

Methanol:water (80:20)

Methanol

Ethanol:water (20:80)

Ethanol:water (40:60)

Ethanol:water $(60: 40)$

Ethanol:water (80:20)

Ethanol
TPC

(mg GAE/g DW)

Bark

$29.7 \pm 2.4$

$34.0 \pm 3.2$

$38.1 \pm 3.7$

$39.2 \pm 3.1$

$39.4 \pm 3.2$

$17.5 \pm 1.7$

$35.7 \pm 0.5$

$39.3 \pm 3.2$

$41.1 \pm 1.7$

$41.3 \pm 3.5$

$18.2 \pm 0.8$
Core

$10.7 \pm 0.4$

$15.0 \pm 1.3$

$19.7 \pm 1.0$

$20.7 \pm 1.8$

$19.9 \pm 1.9$

$13.4 \pm 1.1$

$17.1 \pm 0.7$

$20.2 \pm 1.2$

$23.0 \pm 1.9$

$23.6 \pm 2.2$

$10.4 \pm 0.9$

T'PC: total phenolic content.

$\mathrm{b}$ mg GAE/g DW: mg gallic acid equivalents/g dry weight. 
Extraction temperature is another crucial parameter in the recovery of polyphenols. In this study, three temperatures, namely 60,100 and $120^{\circ} \mathrm{C}$, were tested on bark and core samples for pure water, $60 \%$ aqueous ethanol and $60 \%$ aqueous methanol. The selection of these temperatures was based on previous data from the literature (Liazid et al., 2007, Tsubaki et al., 2010). According to the results from Liazid et al. (2007), the majority of phenolic compounds can be extracted without degradation at temperatures up to $125^{\circ} \mathrm{C}$ for an extraction time of $20 \mathrm{~min}$. TPC for each tested condition is presented in Table 4. The obtained results revealed that the increase of extraction temperature from $60{ }^{\circ} \mathrm{C}$ to $120^{\circ} \mathrm{C}$ improved the polyphenols yields. In fact, TPC values were very similar for $60 \%$ aqueous ethanol or methanol at $100{ }^{\circ} \mathrm{C}$ or $120^{\circ} \mathrm{C}$, which mean that no significant polyphenols degradation occurred. These results are also in accordance with the results previous obtained for solvent composition (Table 3). Therefore, as ethanol is a food grade and ecofriendly solvent (Dai and Mumper, 2010, Lazar et al., 2016), for the subsequent RSM optimization studies, $60 \%$ aqueous ethanol was selected as the optimum extraction solvent. 
Table 4. Evaluation of microwave-assisted extraction temperature effect on the total phenolic content (mean \pm standard deviation, $n=3$ ) of bark and core samples collected during 2015. Other operational conditions: $20 \mathrm{~mL}$ of solvent, $0.5 \mathrm{~g}$ sample, $15 \mathrm{~min}$ and medium stirring speed.

\begin{tabular}{|c|c|c|c|}
\hline \multirow[t]{2}{*}{ Solvent Composition (v/v) } & \multirow[t]{2}{*}{ Temperature $\left({ }^{\circ} \mathrm{C}\right)$} & \multicolumn{2}{|c|}{$\begin{array}{l}\text { TPC }^{\mathrm{a}} \\
(\mathrm{mg} \mathrm{GAE} / \mathrm{g} \mathrm{DW})^{\mathrm{b}}\end{array}$} \\
\hline & & Bark & Core \\
\hline Water & 60 & $18.0 \pm 1.6$ & $4.9 \pm 0.4$ \\
\hline Methanol:water (60:40) & & $28.8 \pm 1.3$ & $16.1 \pm 1.1$ \\
\hline Ethanol:water $(60: 40)$ & & $32.0 \pm 2.4$ & $11.7 \pm 1.1$ \\
\hline Water & 100 & $29.7 \pm 2.4$ & $10.7 \pm 0.4$ \\
\hline Methanol:water (60:40) & & $39.2 \pm 3.1$ & $20.7 \pm 1.8$ \\
\hline Ethanol:water $(60: 40)$ & & $41.1 \pm 1.7$ & $23.0 \pm 1.9$ \\
\hline Water & 120 & $27.2 \pm 1.3$ & $10.4 \pm 0.5$ \\
\hline Methanol:water $(60: 40)$ & & $41.8 \pm 1.8$ & $18.7 \pm 1.2$ \\
\hline Ethanol:water $(60: 40)$ & & $37.7 \pm 2.8$ & $21.8 \pm 1.1$ \\
\hline \multicolumn{4}{|l|}{ a } \\
\hline \multicolumn{4}{|c|}{ T'PC: total phenolic content. } \\
\hline $\mathrm{b}$ & & & \\
\hline
\end{tabular}

Since the extraction yield can also be affected by the accessibility of the solvent to the sample (Chan et al., 2011), the efficiency of MAE of phenolic compounds by $60 \%$ aqueous ethanol using different sample weight:solvent volume ratios $(0.10: 20-1.0: 20, \mathrm{w} / \mathrm{v})$ for two temperatures ( 100 and $120^{\circ} \mathrm{C}$ ) was also compared. It can be seen in Table 5 that, when the solid/liquid ratio decreased the TPC increased. These results agree with those reported by Yang et al. (2009), and can be explained by the presence of a larger volume of solvent which can accelerate the diffusion of compounds increasing the polyphenols yield (MuñizMárquez et al., 2013). Also, the increase of temperature for the lower solid/liquid ratios 
(0.1:20 and 0.5:20, w/v) decreased slightly the yield of polyphenols extracted. This behavior was observed for both samples analyzed. Overall, the best results were reached using the lowest solid/liquid ratio $(0.1: 20, \mathrm{w} / \mathrm{v})$ at $100^{\circ} \mathrm{C}$.

Table 5. Evaluation of microwave-assisted extraction sample weight:solvent volume ratio effect on the total phenolic content (mean \pm standard deviation, $n=3$ ) of bark and core samples collected during 2015. Other operational conditions: $20 \mathrm{~mL}$ of ethanol:water (60:40), $15 \mathrm{~min}$ and medium stirring speed.

Sample weight:solvent volume ratio $(\mathrm{g} / \mathrm{mL})$

$0.1: 20$

$0.5: 20$

1.0:20

$0.1: 20$

$0.5: 20$

1.0:20
Temperature $\left({ }^{\circ} \mathrm{C}\right) \quad \mathrm{T}^{\prime} \mathrm{PC}$ (mg GAE/g DW) ${ }^{\mathrm{b}}$

Bark Core

100

$42.0 \pm 3.9 \quad 26.7 \pm 0.9$

$41.1 \pm 1.7 \quad 23.0 \pm 1.9$

$32.4 \pm 1.6 \quad 22.0 \pm 0.7$

120

$37.1 \pm 2.3 \quad 24.1 \pm 2.3$

$37.7 \pm 2.8 \quad 21.8 \pm 1.1$

$34.7 \pm 3.2 \quad 24.2 \pm 1.8$

a

TPC: total phenolic content.

$\mathrm{b}$

mg GAE/g DW: mg gallic acid equivalents/g dry weight.

\subsection{Extraction optimization}

The impact of extraction technique, namely the $\mathrm{CE}$ and MAE, on the yield of phenolic compounds recovered from apple tree woods was evaluated in this study. Taking in consideration the results obtained in the preliminary assays (Section 3.1), independent variables for the both optimized extraction techniques were defined. Moreover, as the preliminary results revealed that TPC obtained for bark was 2-fold higher than for core extracts (Table 3-5), and that the influence of variables in bark and core TPC levels was similar, the optimization was performed with the bark samples. 


\subsubsection{Microwave assisted extraction - response surface methodology}

The full optimization of MAE of polyphenols from apple tree bark (Table 2) was made applying a 23 full-factorial central composite design coupled with RSM (Fig. 1S, supplementary material), allowing us to study the impact of all parameters combined on TPC. A response surface regression was performed to fit a mathematical model to the experimental data and the following model equation for the recoded factor values was created:

(2)

$$
\begin{aligned}
Y= & 30.60+1.00 X_{1}-2.19 X_{2}+2.21 X_{3}-0.37 X_{1}^{2}+1.68 X_{2}^{2}+0.35 X_{3}^{2} \\
& +0.40 X_{1} X_{2}-0.68 X_{1} X_{3}-0.66 X_{2} X_{3}
\end{aligned}
$$

By eliminating the non-significant parameters $(p>0.05)$ the second order polynomial model was redefined as:

(3)

$$
Y=30.60+1.00 X_{1}-2.19 X_{2}+2.21 X_{3}+1.68 X_{2}^{2}
$$

Analysis of variance (ANOVA) showed that TPC was significantly influenced $(p<0.05)$ by all the linear terms, as well as by the quadratic effect of sample weight (X2). As desired, yield of second order model (Eqs. (2) and (3)) reached high statistical significance ( $p<$ $0.05)$ and the attained second order model quadratic correlation coefficient $(0.85)$ can be considered acceptable for data of chemical nature, advocating a good correlation between observed and predicted values (Table 2). The optimum conditions predicted by the model were $0.1 \mathrm{~g}$ of sample, $100{ }^{\circ} \mathrm{C}, 33.5 \mathrm{~min}$ and a polyphenol content of $39.8 \mathrm{mg} \mathrm{GAE} / \mathrm{g} \mathrm{DW}$. 3D surface plots (Fig. 1S, Supplementary material) showed that maximum recovery was attained by using a sample weight $<0.2 \mathrm{~g}$, temperature $>110-120{ }^{\circ} \mathrm{C}$ and time $<40 \mathrm{~min}$. Thus, by analyzing all the attained results (including experimental data; Table 2), the optimum microwave conditions for maximizing the extraction efficiency (TPC) and energy 
and time savings were selected as being a low amount of sample $0.1 \mathrm{~g}$, combined with medium stirring speed for 20 min using $20 \mathrm{~mL}$ of $60 \%$ aqueous ethanol at a temperature of $100{ }^{\circ} \mathrm{C}$. Applying these selected optimum conditions, the attained TPC was $39.6 \mathrm{mg} \mathrm{GAE} / \mathrm{g}$ DW, being not statistically different from the one predicted. Observing the RSM plots, slightly higher TPC can be obtained if the extraction is performed at higher temperature. However, since there is a risk of degradation of the most thermo-sensitive compounds (Liazid et al., 2007) causing the loss of valuable polyphenols, $100{ }^{\circ} \mathrm{C}$ was chosen.

\subsubsection{Conventional extraction}

Based on previously published data for other matrices (Dai and Mumper, 2010, Hofmann et al., 2015, Naima et al., 2015) and since no significant differences were found between methanol and ethanol for the yield of phenolic compounds, the effect of organic solvent composition was only studied for ethanol $(0,20,50$ and 80\%) in CE. The achieved results (Table 6) show that the TPC of bark increases significantly (2-fold higher) up to $50 \%$, being not statistically different for $80 \%(p=0.057)$. These results agree with the reported by Yang et al. (2009), that optimized the ethanol concentration for the recovery of polyphenols from the bark of Phyllanthus emblica L. These authors reported an increase in the extraction rate of polyphenols from 30 to $70 \%$, and also concluded that an ethanol concentration higher than $70 \%$ extracts a higher amount of liposoluble materials, which difficult the purification process. Thus, in this study, $50 \%$ of ethanol was selected as the optimum solvent. 
Table 6. Evaluation of conventional extraction operational conditions on the total phenolic content (mean \pm standard deviation, $n=3$ ) of bark samples collected during

2015. Other parameters: $20 \mathrm{~mL}$ of solvent and $0.5 \mathrm{~g}$ sample.

$\begin{array}{ll}\text { Extraction conditions } & \begin{array}{l}\text { TPC }^{\mathrm{a}} \\ (\mathrm{mg} \mathrm{GAE} / \mathrm{g} \mathrm{DW})^{\mathrm{b}}\end{array} \\ \text { Water, } 2 \mathrm{~h}, 20^{\circ} \mathrm{C} & 17.0 \pm 0.8 \\ \text { Ethanol } 20 \%, 2 \mathrm{~h}, 20^{\circ} \mathrm{C} & 24.4 \pm 1.4 \\ \text { Ethanol } 50 \%, 2 \mathrm{~h}, 20^{\circ} \mathrm{C} & 34.4 \pm 0.7 \\ \text { Ethanol } 80 \%, 2 \mathrm{~h}, 20^{\circ} \mathrm{C} & 32.8 \pm 1.4 \\ \text { Ethanol } 50 \%, 6 \mathrm{~h}, 20^{\circ} \mathrm{C} & 34.7 \pm 1.5 \\ \text { Ethanol } 50 \%, 24 \mathrm{~h}, 20^{\circ} \mathrm{C} & 37.2 \pm 2.1 \\ \text { Ethanol } 50 \%, 2 \mathrm{~h}, 55^{\circ} \mathrm{C} & 43.2 \pm 1.4 \\ \quad \text { a } & \\ \quad \text { TPC: total phenolic content. } & \\ \text { b } & \end{array}$

Another parameter optimized for the CE was the extraction time, which was studied for 2, 6 and $24 \mathrm{~h}$, while the other extraction conditions were defined as solid/liquid ratio of $0.5 / 20$ $(\mathrm{g} / \mathrm{mL}), 50 \%$ aqueous ethanol and the water bath temperature of $20{ }^{\circ} \mathrm{C}$. For the tested times, CE performed for $24 \mathrm{~h}$ give a higher TPC when compared to the other extraction times studied $(34.4 \pm 0.7,34.7 \pm 1.5$, and $37.2 \pm 2.1 \mathrm{mg} \mathrm{GAE} / \mathrm{g} \mathrm{DW}$ for 2,6 and $24 \mathrm{~h}$, respectively). Although, no significant differences were achieved in the TPC for the extraction times tested ( $p>0.114$ ), thus $2 \mathrm{~h}$ was selected as the optimum value. Moreover, longer extraction times can induce more chemical reactions and cause oxidative conversion of phenolic compounds, which can influence the real levels (Yang et al., 2009). Hofmamn et al. (2015) investigated the influence of extraction time (2, 5 and $24 \mathrm{~h})$ in the polyphenols recovery from the beech bark, and they found significant differences $(p<0.001)$ for the tested times, with the highest phenolic content obtained for an extraction time of $5 \mathrm{~h} \mathrm{(48.3 \pm}$ $1.2 \mathrm{mg}$ quercetin/g dry bark). In another study, Naima et al. (2015) also reported that the highest polyphenol yield was obtained at lower extraction time $(2 \mathrm{~h})$, which decrease at $6 \mathrm{~h}$ 
and increased again after $24 \mathrm{~h}$ of extraction. They reported that the decrease may be due to the degradation of polyphenols with progressing extraction time, but on the other hand additional substances, such as lignanes, can be extracted increasing the TPC for the $24 \mathrm{~h}$ of extraction.

Taking in consideration possible degradation of phenolic compounds and concerning the literature information (Ghitescu et al., 2015, Lazar et al., 2016, Naima et al., 2015, Yang et al., 2009), tests were conducted at two temperatures (20 and $55{ }^{\circ} \mathrm{C}$ ) using $50 \%$ aqueous ethanol and $2 \mathrm{~h}$ as extraction time (Table 6 ). The yield of polyphenols extracted from bark was highest when using $55^{\circ} \mathrm{C}$ instead of $20^{\circ} \mathrm{C}$. This increase in the extraction yield may be related with the cell wall integrity, which could be weaken by the increase of temperature resulting in a higher contact of the solvent and polyphenols present in sample which reflects in the TPC (Yang et al., 2009). According to the presented results, it was also observed that TPC obtained at $55^{\circ} \mathrm{C}$ during $2 \mathrm{~h}$ was higher than the value obtained at $20^{\circ} \mathrm{C}$ for $24 \mathrm{~h}$, indicating that the temperature has a greater impact on the polyphenols yield than the extraction time in CE. Ghitescu et al. (2015) investigated the influence of temperature (40, 50 and $60{ }^{\circ} \mathrm{C}$ ) for different extraction time (30, 45 and $60 \mathrm{~min}$ ) on polyphenol yield from spruce wood bark, and they also demonstrated that TPC was lower at $40{ }^{\circ} \mathrm{C}$ and $60 \mathrm{~min}$ (8.3 $\mathrm{mg} \mathrm{GAE} / \mathrm{g}$ dry bark) than at $50^{\circ} \mathrm{C}$ and $30 \mathrm{~min}$ ( $9.5 \mathrm{mg} \mathrm{GAE} / \mathrm{g}$ dry bark). In fact, they also showed that for the same extraction time, TPC of spruce bark increased with temperature. Some authors defended that extraction temperature should not be higher than $50{ }^{\circ} \mathrm{C}$ due to the loss of solvent and possible polyphenols oxidation (Lazar et al., 2016, Yang et al., 2009). Although, recently Naima et al. (2015) reported that an increase from 40 to $80{ }^{\circ} \mathrm{C}$ improved the yield of polyphenols at least 3-fold $(76.2 \pm 4.0-279.3 \pm 3.1 \mathrm{mg} \mathrm{GAE} / \mathrm{g}$ bark) from Maroccan bark of Acacia mollissima. According to the obtained experimental results, in the present study the optimal conditions for CE were considered as being $50 \%$ aqueous ethanol, an extraction time of $2 \mathrm{~h}$ at $55^{\circ} \mathrm{C}$. 


\subsection{Characterization of apple tree extracts}

\subsubsection{Phenolic content and antioxidant activity}

The MAE and CE extracts (obtained applying the optimal extraction conditions) from apple tree woods collected during September 2015 and February 2016 were characterized by TPC, TFC, DPPH-RSA and FRAP assays (Fig. 1). As it can be seen (Fig. 1), MAE technique enabled to obtain root extracts collected at 2016 with higher phenolic (44.4 \pm 1.1 $\mathrm{mg} \mathrm{GAE} / \mathrm{g} \mathrm{DW})$ and flavonoid (20.3 $\pm 1.2 \mathrm{mg} E E / \mathrm{g} \mathrm{DW})$ contents, as well as with the highest antioxidant capacity $(29.6 \pm 1.3 \mathrm{mg} \mathrm{TE} / \mathrm{g} \mathrm{DW}$ and $39.8 \pm 2.0 \mathrm{mg} \mathrm{AAE} / \mathrm{g} \mathrm{DW}$ by DPPH-RSA and FRAP assays, respectively) compared to the CE technique for all the samples studied. This behavior was expected since several authors reported the higher efficiency of MAE against the CE technique for wood residues (Aspé and Fernández, 2011, Bouras et al., 2015, Naima et al., 2015). Aspé and Fernández (2011) evaluated the performance of four extraction techniques, namely maceration, Soxhlet extraction, MAE and $\mathrm{UAE}$, for the recovery of phenolic compounds from Pinus radiata bark. The obtained results showed the same trend, with the MAE extracts presenting higher amount of phenolics, tannins and antioxidant capacity, demonstrating that MAE technique was an efficient method for extraction of $P$. radiata bark polyphenols. This difference in results may be related with the main MAE principle (volumetric heating- heat is originated inside the material). MAE is considered as a green extraction process as the time and amount of solvents used are lower in comparison with the CE. Moreover, one of the greater advantages of MAE technique is that the extraction solvent penetrates more easily inside the cell walls and break those linkages between the phenolics and cell walls increasing the amount of phenolic compounds recovered (Drosou et al., 2015). In fact, in the study performed by Aspé and Fernández (2011), the bark surface morphology was examined after the extractions with a scanning electron microscope and they reported that MAE produced a cell destruction, while maceration only resulted in slightly ruptured cell pores, which could explain its low extraction efficiency. Despite of higher yield achieved with MAE, to employ this extraction technique, a more expensive equipment is necessary in comparison to the requirements of $\mathrm{CE}$. Although, in the case of apple tree residues, CE requires $2 \mathrm{~h}$ and MAE takes only $20 \mathrm{~min}$, which means that the extraction time was reduced in $83.3 \%$. Therefore, the application of MAE technique despite of a high initial investment can become more profitable in terms of yield, and time and money savings. 

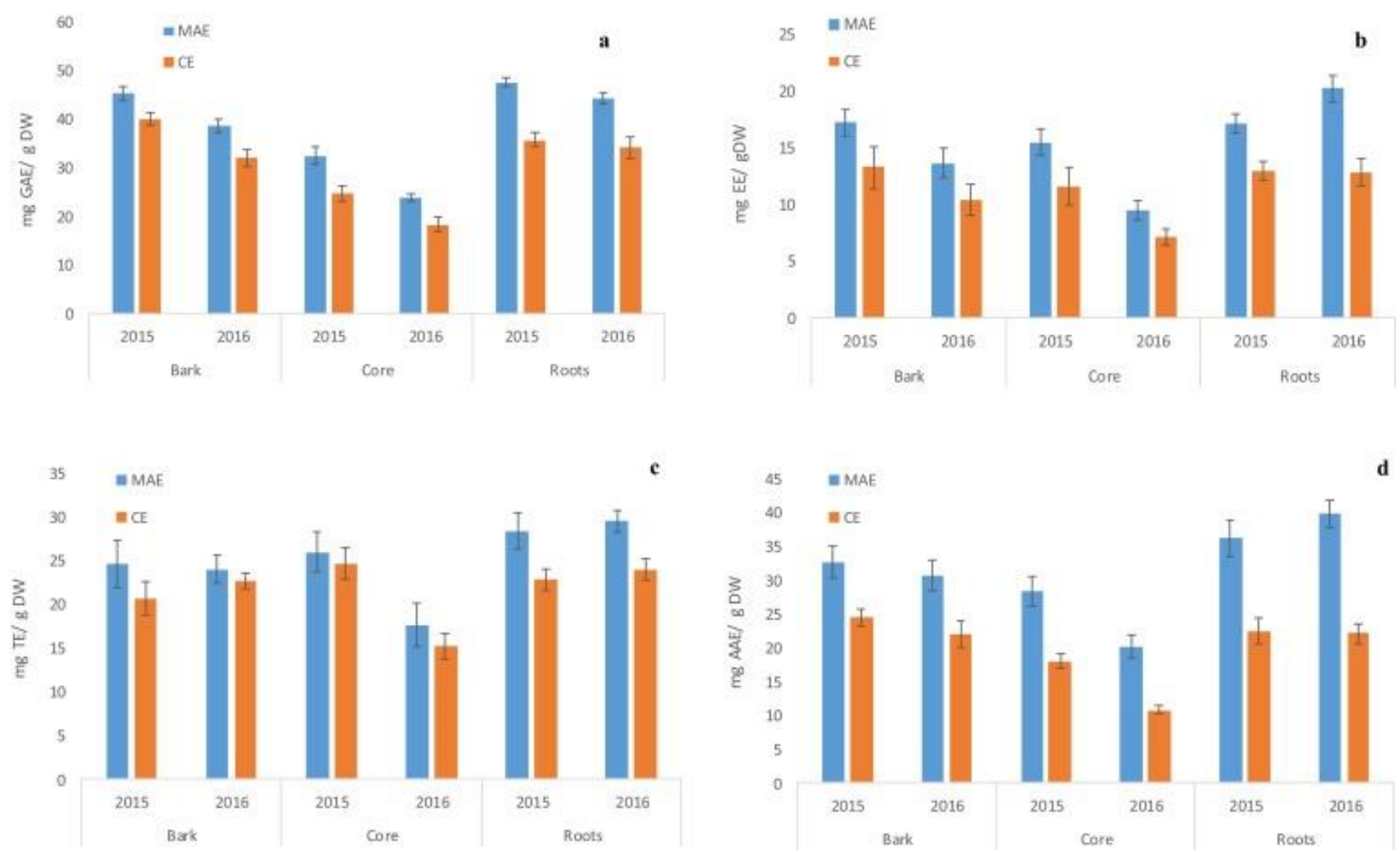

Fig. 1. Comparison of microwave-assisted extraction (MAE) with conventional extraction (CE) for (a) total phenolic content (mg gallic acid equivalent/g dry weight), (b) total flavonoid content (mg epicatechin equivalent/g dry weight), (c) DPPH-RSA, 2,2-diphenyl-1-picrylhydrazyl radical scavenging activity (mg trolox equivalents/g dry weight) and (d) FRAP, ferric reduction activity power (mg ascorbic acid equivalents/g dry weight) of different apple wood residues; results are expressed as mean \pm standard deviation, $n=3$.

Concerning the differences between the samples (Fig. 1), there is an ongoing trend for all the applied assays in the characterization of apple tree extracts with roots presenting the highest phenolic and flavonoid content, as well as the highest antioxidant capacity followed by bark, and core samples. This variation may be explained by the ability of phenolic compounds, which can be found in soil, to bind to organic nitrogen sources, which are useful for the tree (El Gharras, 2009, Hofmann et al., 2015, Kähkönen et al., 1999). Thus, these compounds can be absorbed by the roots and transported further to the apple tree. Roots function is the absorption of the necessary water and minerals for the tree, but on the other hand, roots are highly exposed to diverse atmospheric conditions, insects, and bacteria. Therefore, apple tree roots need to behave as a strong agent to protect the tree from threats existing in soil, which means that they need to absorb higher amount of phenolics to prevent these threats. As bark shields the core, it will protect it from several elements such as wind, rain, insects, and possible infections, thus bark needs more 
phenolic compounds than core. This explanation can justify the distinction between roots, bark and core extracts. For the TPC and TFC assays, there are significant differences between the analyzed samples, with root extracts presenting the highest phenolic and flavonoid content in comparison to bark or core extracts. In fact, for samples collected during 2016, this variation is more pronounced, as TPC is at least 2-fold higher for bark (38.7 $\pm 1.4 \mathrm{mg} \mathrm{GAE} / \mathrm{g} \mathrm{DW})$ or roots $(44.4 \pm 2.2 \mathrm{mg} \mathrm{GAE} / \mathrm{g} \mathrm{DW})$ in comparison to core (23.8 $\pm 0.8 \mathrm{mg} \mathrm{GAE} / \mathrm{g} \mathrm{DW}$ ). The same tendency was found for the flavonoid content. Regarding the assays for the measurement of antioxidant capacity, no significant differences between the samples or the season of collection from samples were detected. Significant changes were only detected for core collected at 2016, which in comparison with the other samples presented the lowest antioxidant capacity. Several studies indicated that the antioxidant capacity is related to the phenolic content (Aspé and Fernández, 2011, Lamounier et al., 2012). Therefore, this result was expected since, in the total phenolic and total flavonoid assays, it was already the sample with the lowest content. As previously mentioned, this significant distinction between the bark or roots and core samples may be related to the function that this apple tree residues exerts accumulating phenolics and flavonoids in vacuoles, which contribute to the development and protection against infection and injury of plants (El Gharras, 2009, Hofmann et al., 2015). Regarding the influence of the collection season (Fig. 1), there is not a marked trend. Although, it may be noticed that samples collected during Summer 2015 presented the highest values in comparison with samples from Winter 2016. This slight variation may be caused by the atmospheric conditions that apple trees are subjected before the collection of the sample, which can result in dissimilar phenolic composition and antioxidant properties (Zhang et al., 2015). In fact, the results obtained by Chupin et al. (2013) agreed with these findings, demonstrating that trees subjected to higher sun exposure (namely the samples collected in September of 2015) have an higher phenolic content comparing with the shaded trees.

This is the first paper evaluating the phenolic composition and the antioxidant properties from the apple tree residues, namely from bark, core and roots. According to the reported data in literature (Table 1), different types of tree and distinct parts of the tree enable to obtain diverse phenolic contents. The results achieved in this work agree with some of the results found in the studies reported in Table 1. Using a similar CE technique in bark from the Maroccan Acacia mollissima, the TPC values found were 8-20 times higher than any of 
the samples used in this work. In this study, the TPC from CE extracts ranged from $18.4 \pm$ 1.6 to $40.2 \pm 1.4 \mathrm{mg} \mathrm{GAE} / \mathrm{g}$ DW, while the value reported by Naima et al. (2015) was 353.6 $\pm 0.5 \mathrm{mg} \mathrm{GAE} / \mathrm{g}$ bark. In the opposite way, the TPC obtained for oak wood from different countries was at least 360 times lower (TPC values ranged from $25.3 \pm 0.4$ to $51.0 \pm 1.6 \mu \mathrm{g}$ GAE/g oak wood) (Alañón et al., 2011) than the values found for samples from this work. Other CE techniques reported in literature for samples similar to the ones investigated in this work are infusion (Naima et al., 2015) and Soxhlet extraction (Gao et al., 2007). For both studies, the attained TPC values were higher than the ones found in this work (258.4 \pm 3.6 mg GAE/g bark (Naima et al., 2015) and 77.7-88.8 mg GAE/g bark (Gao et al., 2007) vs $18.4 \pm 1.6-40.2 \pm 1.4 \mathrm{mg} \mathrm{GAE} / \mathrm{g}$ bark). Concerning the application of recent extraction techniques, such as MAE, in this type of wood residues, the majority of published studies are from the last two years (Table 1) demonstrating the novelty of this study. Comparing the results obtained in the present study for bark with the values reported in Table 1, the differences within the values obtained for the TPC could be related not only with the matrix studied, but they are also dependent of the applied extraction conditions (Drosou et al., 2015).

\subsubsection{Phenolic composition by HPLC-PDA analysis}

Apple tree wood extracts obtained by MAE and CE techniques were also characterized by HPLC-PDA to find which phenolic compounds were contributing to their antioxidant properties. Results are exhibited in Table 7 while representative chromatograms are presented in Fig. 2. According to the obtained results, flavonoid compounds were the main contributors to the phenolic profile, and phenolic acids represents less than $10 \%$ of all quantified compounds. HPLC analysis revealed that phloridzin was the main contributor to the phenolic composition for all the analyzed extracts representing $52 \%$ to $87 \%$ of the total amount of phenolic compounds quantified. Despite of the lack of studies regarding these apple tree residues, other authors (Liaudanskas et al., 2014, Rana et al., 2016, Walia et al., 2016) also reported that apple tree leaves accumulate high amounts of phloridzin, a dihydrochalcone, which health benefits have been widely studied specially in glucose uptake and diabetes. Therefore, it is not surprising that apple tree residues were mostly composed by this phenolic compound. In the present study, the highest content of phloridzin was $0.40 \mathrm{mg} / \mathrm{g} \mathrm{DW}$, which is close to the value reported in apple tree leaves by Rana et al. (2016) $(0.15 \pm 0.05 \mathrm{mg} / \mathrm{g})$, whereas lower than the content reported by Liaudanskas et al. (2014) (1.40 $\pm 0.0-2.40 \pm 0.09 \mathrm{mg} / \mathrm{g} \mathrm{DW})$. Besides phloridzin, another 
four flavonoids were identified in the majority of the extracts as the most abundant, namely myricetin, kaempferol-3-O-glucoside, naringin and quercetin-3-O-glucopyranoside. In the case of myricetin and kaempferol-3-O-glucoside, the higher contribution to the total amount of phenolic compounds quantified corresponds to approximately $16 \%$ and $12 \%$, respectively, for core wood collected during 2015 for both extraction techniques applied. The contribution of these compounds, and from naringin and quercetin-3-Oglucopyranoside compounds, to the other apple residues extracts were less than $3 \%$. None of these compounds were identified in apple tree leaves (Liaudanskas et al., 2014, Rana et al., 2016, Walia et al., 2016).

Table 7. Content (mean \pm standard deviation, $n=3$ ) of the identified phenolic compounds in apple tree wood extracts obtained by microwave-assisted extraction (MAE) and conventional extraction (CE) techniques. 


\begin{tabular}{|c|c|c|c|c|c|c|c|c|c|c|c|c|}
\hline \multirow[t]{2}{*}{ 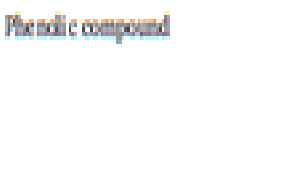 } & \multicolumn{2}{|c|}{ 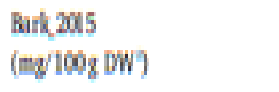 } & \multicolumn{2}{|c|}{$\begin{array}{l}\text { Rumbl6 } \\
\text { malos DW }\end{array}$} & \multicolumn{2}{|c|}{$\begin{array}{l}\text { Gar } 215 \\
(2 / 1010 \%)\end{array}$} & \multicolumn{2}{|l|}{ 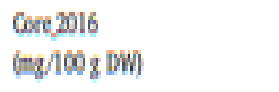 } & \multicolumn{2}{|c|}{ 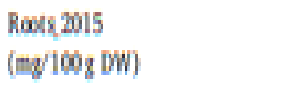 } & \multicolumn{2}{|l|}{ 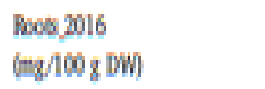 } \\
\hline & MAE & $\mathbf{a}$ & $M \bar{C}$ & $\mathrm{GE}$ & MAs & $\mathbf{a}$ & $\mathrm{M} \overline{\mathrm{B}}$ & $\overline{\mathrm{R}}$ & MEE & $\bar{a}$ & Me & $\overline{\mathrm{CR}}$ \\
\hline Galkad & $H i \pm 10$ & 체 $5 \pm 1$ & $\$ 1 \pm 01$ & $04+9 \pm 000$ & $\mathrm{ND}$ & $1 k \pm \pm 0$ & $4+4 \pm d 2$ & $14 \pm 010$ & $438 \pm 05$ & $49 \pm 15$ & $<\omega 0$ & $1,4 \pm 010$ \\
\hline Powowisty add & $7.2 \pm 04$ & $75 \pm 04$ & $2 s \pm 10$ & $26 \pm 01$ & $2.9 \pm 1.4$ & $46 \pm 02$ & $183 \pm 09$ & $381 \pm 018$ & $22 \pm 1.2$ & $371 \pm 04$ & $186 \pm 09$ & $39 \pm 02$ \\
\hline (t)ownth & $37 \pm 1.5$ & $189 \pm 09$ & $9.7 \pm 46$ & $87 \pm 04$ & $3 \| \pm 1.5$ & $159 \pm 0.8$ & $103 \pm 0.5$ & $841 \pm 042$ & $51.2 \pm 26$ & $21.9 \pm 1.1$ & $642 \pm 32$ & $109 \pm 05$ \\
\hline 4horghallawe ad & $\leq 100^{\circ}$ & $<100$ & $\angle L O D$ & $<100$ & $67 \pm 34$ & $177 \pm 24$ & $395 \pm 1.9$ & $7.4 \pm 14$ & $<100$ & $\leq 100$ & $<100$ & $\leq L O D$ \\
\hline 4hipughawe ard & $453 \pm 23$ & $432 \pm 22$ & $43 \pm 20$ & $37.2 \pm 1.9$ & IL $L D$ & $4 \mathrm{WD}$ & $\mathbb{4} 100$ & is $L D$ & $401 \pm 25$ & $473 \pm 24$ & $426 \pm 21$ & $39 \pm 19$ \\
\hline 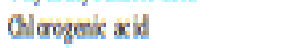 & $189 \pm 09$ & $175 \pm 09$ & $31 \pm 26$ & $41.7 \pm 21$ & $<\omega 0$ & $<100$ & $185 \pm 04$ & $764 \pm 0.48$ & $31.9 \pm 16$ & $196 \pm 09$ & $x t \pm 1.8$ & $210 \pm 12$ \\
\hline Vallind & $<100$ & $<100$ & 400 & $<100$ & \& LOO & $<100$ & $<100$ & $<100$ & $36 \pm 02$ & 100 & $<100$ & 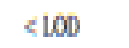 \\
\hline Geffer an & $<100$ & $<100$ & 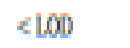 & $\approx \Delta 0$ & 400 & $<100$ & 400 & 100 & $7 B \pm 04$ & $<100$ & $\Delta B \pm 04$ & $\angle 00$ \\
\hline shing aid & $150 \pm 08$ & $145 \pm 07$ & $20 \pm 1.4$ & $41.7 \pm 21$ & $113 \pm 0 b$ & $102 \pm 0.5$ & $<100$ & $154 \pm 08$ & $<100$ & $4 x+0.21$ & $<100$ & $25 \pm 16$ \\
\hline 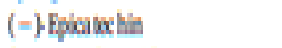 & $245 \pm 02$ & $152 \pm 0.3$ & $\mathbb{L} L D$ & $1.46 \pm 0.7$ & $\mathbb{L} L \omega$ & $4 \mathrm{HD}$ & 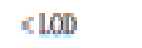 & $1.46 \pm 607$ & $x \operatorname{lol}$ & $107 \pm 0.5$ & 4 $L D$ & $1.46 \pm 007$ \\
\hline H knople and & $52 \pm 26$ & $<100$ & $36 \pm 28$ & $<100$ & $<100$ & $<00$ & $<100$ & $<100$ & $66 \pm 33$ & $<00$ & $55 \pm 28$ & $<100$ \\
\hline Forlika a d & $121 \pm 06$ & $125 \pm 06$ & $87 \pm 04$ & $063 \pm 000$ & $89 \pm 04$ & $301 \pm 015$ & $40 \pm 020$ & $181 \pm 009$ & $66 \pm 03$ & $182 \pm 09$ & $44 \pm 02$ & $1.5 \pm 00$ \\
\hline suph ad & $176 \pm 09$ & $192 \pm 00$ & $63 \pm 03$ & $051 \pm 00$ & $<100$ & $7 \mathrm{~T} \pm 0 \mathrm{H}$ & $60 \pm 02$ & $417 \pm 021$ & $486 \pm 04$ & $62 \pm 33$ & $45 \pm 024$ & $26+ \pm 013$ \\
\hline Nuing & $167 \pm 53$ & $121.2 \pm 61$ & $65 \pm 32$ & $34 \pm 29$ & $182 \pm 09$ & $29 \pm 0.15$ & $<L O D$ & $237 \pm 012$ & $12 \pm 6$ & $115 \pm 6$ & $745 \pm 07$ & $61.3 \pm 06$ \\
\hline Ruth & $727 \pm 06$ & $6.8 \pm 32$ & $80 \pm 04$ & $919 \pm 0.6$ & $9.84 \pm 046$ & $109 \pm 06$ & $68 \pm 04$ & $810 \pm 041$ & $81 \pm 03$ & $404 \pm 20$ & $6 x+03$ & $624 \pm 031$ \\
\hline Rosisid & $\mathrm{K} 1 \pm 1.2$ & $20 \pm 1.1$ & $\mathbf{2 1} \pm 1.0$ & $160 \pm 08$ & $20 \pm 16$ & $20 \pm 1.0$ & $157 \pm 08$ & $67 \pm 04$ & $<100$ & $<100$ & $<100$ & $<L O D$ \\
\hline 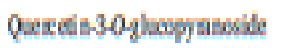 & $14.8 \pm 67$ & $111.8 \pm 56$ & $24 \pm 49$ & $8.7 \pm 4.8$ & $\operatorname{LiD}$ & $4 \mathrm{WD}$ & 4100 & 100 & $1116 \pm 56$ & $91.9 \pm 4.6$ & $724 \pm 36$ & $51.7 \pm 26$ \\
\hline Whanth & $216 \pm 146$ & $w 1 \pm k$ & $w \pm 10$ & $216 \pm 10$ & 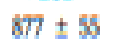 & $\Delta=18$ & $64 \pm$ & $74 \pm 13$ & $36 \pm 1+7$ & $2 k \pm 117$ & 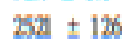 & $240 \pm 11 \%$ \\
\hline Onand and & $512 \pm 27$ & $51.2 \pm 26$ & $0.2 \pm 25$ & $132 \pm 22$ & $81.5 \pm 4.1$ & $61.5 \pm 11$ & $403 \pm 20$ & $20 \pm 10$ & $84 \pm 29$ & $04 \pm 25$ & $487 \pm 24$ & $123 \pm 21$ \\
\hline Mrinth & $m 9 \pm 49$ & $20 \pm 46$ & $20 \pm 46$ & $21 \pm 42$ & $30 \pm 13$ & $z 7 \pm 12$ & $10 \pm 10$ & $10 \pm 5$ & $70 \pm 40$ & $640 \pm 3 x$ & $64 \pm 35$ & $56 \pm 25$ \\
\hline Raplod 30glwads & $29 \pm 1.1$ & $189 \pm 09$ & $189 \pm 09$ & $129 \pm 06$ & $1 \% \pm 9$ & $174 \pm 9$ & $19 \pm 8$ & $101 \pm 5$ & $\boldsymbol{n} 7 \pm 1.1$ & $1810 \pm 091$ & $159 \pm 08$ & $109 \pm 05$ \\
\hline 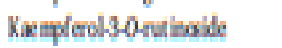 & 38.81 .8 & $28 \pm 1.6$ & $28 \pm 16$ & $258 \pm 1.3$ & $|6| \pm 08$ & $121 \pm 06$ & $70 \pm 0 x$ & is 100 & $x \operatorname{lol}$ & IOD & $\llbracket 100$ & 100 \\
\hline Natingth & $79 \pm 04$ & $<100$ & $16 \pm 01$ & $34 \pm 02$ & 400 & $<100$ & $30 \pm 016$ & $7 \overline{7} \pm 0.5$ & $<\omega \overline{0}$ & $<00$ & $10 \overline{7} \pm 0.5$ & $13 j \pm 07$ \\
\hline QResi & $216 \pm 1.1$ & $27 \pm 1.0$ & $2.4 \pm 1.1$ & $26 \pm 013$ & $29 \pm 1.2$ & $912 \pm 0.46$ & $214 \pm 1.1$ & $7.12 \pm 0 \mathrm{~W}$ & $487 \pm 24$ & $2 \pi \pm 104$ & 5y \pm 1.3 & $75 \pm 03$ \\
\hline Fhenth & म11 $2 \pm 06$ & $155 \pm 05$ & $75 \pm 06$ & $121 \pm 09$ & $167 \pm 06$ & $116 \pm 0.6$ & $190 \pm 06$ & $42 \pm 040$ & $x 2 \pm 13$ & $4 i 7 \pm 1 . j 1$ & $34 \pm 20$ & $275 \pm 09$ \\
\hline Kanplod & $01 \pm 1.5$ & $185 \pm 69$ & $\mathbf{3 1} \pm 13$ & $125 \pm 06$ & $21.9 \pm 1.1$ & $179 \pm 09$ & $12 \pm 0 b$ & 68704 & $36 \pm 1.9$ & $17 b 1 \pm 0 s$ & $121 \pm 06$ & $789 \pm 039$ \\
\hline 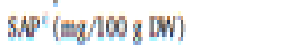 & $3 m \pm 16$ & $34 \pm 18$ & $x+1 B$ & $277 \pm 134$ & $16 \% \pm 8$ & $1518 \pm 76$ & $|W| \pm 6$ & $160 \pm 5$ & $34 \pm 1 W$ & 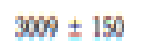 & $312 \pm 157$ & $773 \pm 137$ \\
\hline
\end{tabular}

"W: do widh

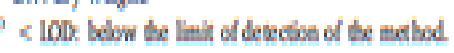

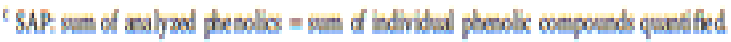




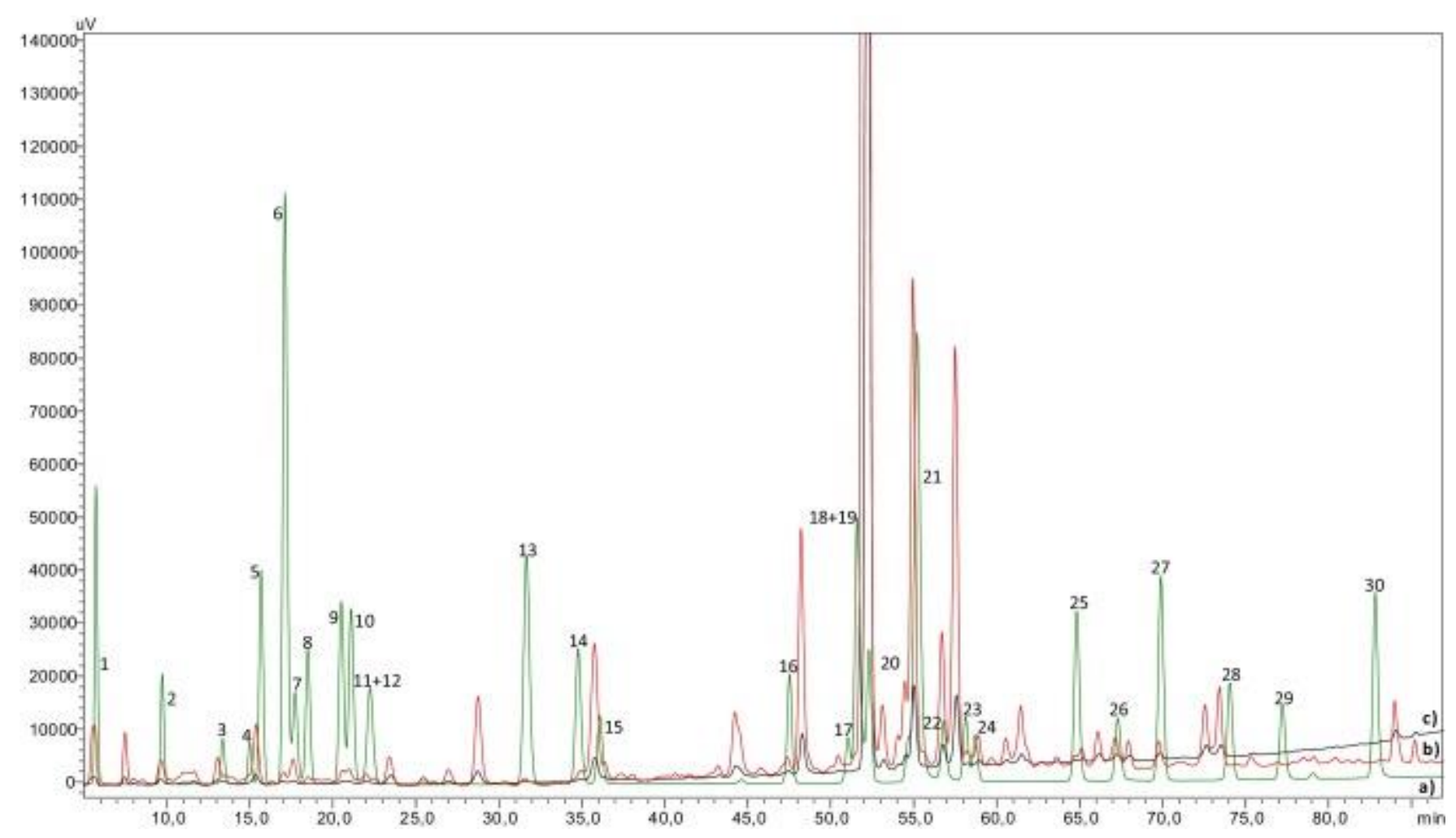

Fig. 2. HPLC chromatograms at $280 \mathrm{~nm}$ for a) polyphenols standard mixture of $5 \mathrm{mg} / \mathrm{L}$, and roots extract collected at 2015 obtained after the application of b) MAE (conditions: $20 \mathrm{~mL}$ of $60 \%$ aqueous ethanol, $100{ }^{\circ} \mathrm{C}, 20 \mathrm{~min}, 0.08 \mathrm{~g}$, and medium stirring speed) and c) $\mathrm{CE}$

(conditions: $20 \mathrm{~mL}$ of $50 \%$ aqueous ethanol, $55^{\circ} \mathrm{C}, 2 \mathrm{~h}, 0.5 \mathrm{~g}$ ); (1) gallic acid, (2) protocatechuic acid, (3) (+)-catechin, (4) 4hydroxyphenilacetic acid, (5) 4-hydroxybenzoic acid, (6) 4-hydroxybenzaldehyde, (7) chlorogenic acid, (8) vanillic acid, (9) caffeic acid, (10) syringic acid, (11) (-)-epicatechin, (12) $\beta$-resorcylic acid, (13) p-coumaric acid, (14) ferulic acid, (15) sinapic acid, (16) naringin, (17) rutin, (18) resveratrol, (19) quercetin-3-O-glucopyranoside, (20) phloridzin, (21) cinnamic acid, (22) myricetin, (23) kaempferol-3-Oglucoside, (24) kaempferol-3-O-rutinoside, (25) naringenin, (26) quercetin, (27) phloretin, (28) tiliroside, (29) kaempferol and (30) pinocenbrim.

The highest content of phenolic acids identified and quantified by the HPLC-PDA analysis (344.6 mg/100 g DW) was reported for roots sampled during 2015 and obtained by MAE (Table 7). Concerning the apple tree wood composition in phenolic acids, an interesting finding was the presence of 4-hydroxybenzoic acid in the extracts of bark and roots, and its non-detection in core. On the other hand, the acid 4-hydroxyphenylacetic was only reported for core extracts. The presence of $\beta$-resorcylic acid was only reported in the bark and root extracts obtained through the MAE technique and not in the CE extracts. These phenolic composition differences in apple tree residues reflect not only the composition of the studied samples, but also the applied extraction techniques. Several investigations have reported that MAE can prevent some polyphenols degradation, which can occur in CE due to the longer extraction times used (Azmir et al., 2013, Hofmann et al., 2015). Moreover, changes in sample collection dates (September 2015 and February 2016) could also affect the 
phenolic profiles, as Belgium climatic conditions were very different at the two dates of sample collection. Comparing these results with the literature available, none of these phenolic acids were detected in apple tree leaves (Liaudanskas et al., 2014, Rana et al., 2016, Walia et al., 2016).

Regarding the comparison of the total amount of phenolic compounds quantified by the HPLC analysis (SAP, sum of analyzed phenolics) and the content obtained through the FCmethod, the same trend for both extraction techniques was followed, with extracts collected during summer and obtained by the MAE technique with higher SAP and TPC values. From the apple tree residues studied, roots and bark represent the wood residues with the highest TPC and SAP. The slight difference between the results obtained by the HPLC analysis and FC-method could be related to the interferences that TPC assay is subjected to, such as sugars or proteins, which could cause overestimated results (Kähkönen et al., 1999). Moreover, the HPLC quantification was made only with the phenolic standards available, which could result in a lower amount than the real value. As can be seen in Fig. 2 , there are some compounds that have not been identified and quantified, which could also justify these differences in the amount achieved. In a future work, it will be interesting to analyze apple tree residues by HPLC with mass spectrometry detection in order to identify and quantify the unknown compounds, which may correspond to phenolics and thereby contribute to the antioxidant properties of the produced extracts.

\section{Conclusions}

The results of this study demonstrated for the first time that Belgium apple tree residues, especially bark and roots, can be a potential source for recovery of phenolic compounds for further application in food, cosmetic, pharmaceutical and other related industries. CE and MAE techniques were optimized to achieve the highest phenolic and flavonoid content, as well as the highest antioxidant activity, for bark, core and roots extracts. From the analyzed samples, root extracts obtained after the application of optimal conditions of MAE $(20 \mathrm{~mL}$ ethanol:water $60: 40 \mathrm{v} / \mathrm{v}, 20 \mathrm{~min}, 100^{\circ} \mathrm{C}$, sample weight $0.1 \mathrm{~g}$ ) and CE (20 mL ethanol:water $50: 50 \mathrm{v} / \mathrm{v}, 2 \mathrm{~h}, 55^{\circ} \mathrm{C}$, sample weight $0.5 \mathrm{~g}$ ) and collected during summer 2015 presented the highest polyphenols yields ( $47.7 \pm 0.9$ and $35.8 \pm 1.4 \mathrm{mg} \mathrm{GAE} / \mathrm{g} \mathrm{DW}$, respectively), followed by bark and core extracts. Furthermore, HPLC-PDA analysis enables to conclude 
that apple tree residues were mainly composed by phloridzin, followed by quercetin-3-Oglucopyranoside, naringin, myricetin and kaempferol-3-O-glucoside.

\section{Acknowledgments}

Manuela M. Moreira (SFRH/BPD/97049/2013) and M. F. Barroso (SFRH/BPD/78845/2011) are grateful for their postdoctoral fellowships financed by POPH-QREN - Tipologia 4.1 Formação Avançada, subsidized by Fundo Social Europeu and Ministério da Ciência, Tecnologia e Ensino Superior. Authors are also grateful for financial support from project NORTE-01-0145-FEDER-000011-311 Qualidade e Segurança Alimentar - uma abordagem (nano) tecnológica. The financial support from FCT/MEC through national funds and cofinanced by FEDER, under the Partnership Agreement PT2020 through the project UID/QUI/50006/2013 - POCI/01/0145/FERDER/007265; the project 6818 - Transnational Cooperation, Agreement between Portugal (FCT) and Serbia (MSTD) is also acknowledged. Annick Boeykens wishes to acknowledge Odisee for funding by means of a PWO grant (Flemish Government).

\section{References}

sAlañón, M.E., Castro-Vázquez, L., Díaz-Maroto, M.C., Hermosín-Gutiérrez, I., Gordon,M.H., Pérez-Coello, M.S., 2011. Antioxidant capacity and phenolic composition ofdifferent woods used in cooperage. Food Chem. 129, 1584-1590.

Aspé, E., Fernández, K., 2011. The effect of different extraction techniques on extractionyield, total phenolic, and anti-radical capacity of extracts from Pinus radiata Bark.Ind. Crops Prod. 34, 838-844.

Azmir, J., Zaidul, I.S.M., Rahman, M.M., Sharif, K.M., Mohamed, A., Sahena, F., Jahurul,M.H.A., Ghafoor, K., Norulaini, N.A.N., Omar, A.K.M., 2013. Techniques forextraction of bioactive compounds from plant materials: a review. J. Food Eng. 117,426436.

Bocalandro, C., Sanhueza, V., Gómez-Caravaca, A.M., González-Álvarez, J., Fernández,K., Roeckel, M., Rodríguez-Estrada, M.T., 2012. Comparison of the composition 
ofPinus radiata bark extracts obtained at bench- and pilot-scales. Ind. Crops Prod. 38,2126.

Bouras, M., Chadni, M., Barba, F.J., Grimi, N., Bals, O., Vorobiev, E., 2015. Optimizationof microwave-assisted extraction of polyphenols from Quercus bark. Ind. Crops Prod.77, 590601.

Carvalho, A.P., Mendes, M., Moreira, M.M., Cruz, D., Magalhães, J.M.C.S., Barroso, M.F.,Ramalhosa, M.J., Duarte, A., Guido, L., Gomes, A.M., Matos, C.D., 2016. Microwaveassisted extraction in goji berries: effect on composition and bioactivity, evaluatedthrough conventional and nonconventional methodologies. Int. J. Food Sci. Technol.51, 1401-1408.

Chan, C.-H., Yusoff, R., Ngoh, G.-C., Kung, F.W.-L., 2011. Microwave-assisted extractionsof active ingredients from plants. J. Chromatogr. A 1218, 6213-6225.

Chupin, L., Motillon, C., Charrier-El Bouhtoury, F., Pizzi, A., Charrier, B., 2013. Characterisation of maritime pine (Pinus pinaster) bark tannins extracted underdifferent conditions by spectroscopic methods, FTIR and HPLC. Ind. Crops Prod. 49,897-903.

Chupin, L., Maunu, S.L., Reynaud, S., Pizzi, A., Charrier, B., Charrier-El Bouhtoury, F.,2015. Microwave assisted extraction of maritime pine (Pinus pinaster) bark: impactof particle size and characterization. Ind. Crops Prod. 65, 142-149.

Dai, J., Mumper, R.J., 2010. Plant phenolics: extraction, analysis and their antioxidantand anticancer properties. Molecules 15, 7313.

Dedrie, M., Jacquet, N., Bombeck, P.-L., Hébert, J., Richel, A., 2015. Oak barks as rawmaterials for the extraction of polyphenols for the chemical and pharmaceuticalsectors. A regional case study. Ind. Crops Prod. 70, 316-321.

Deng, Y., Zhao, Y., Padilla-Zakour, O., Yang, G., 2015. Polyphenols, antioxidant andantimicrobial activities of leaf and bark extracts of Solidago canadensis L. Ind. CropsProd. 74, 803-809.

Drosou, C., Kyriakopoulou, K., Bimpilas, A., Tsimogiannis, D., Krokida, M., 2015. Acomparative study on different extraction techniques to recover red grape pomacepolyphenols from vinification byproducts. Ind. Crops Prod. 75 (Part B), 141-149. 
El Gharras, H., 2009. Polyphenols: food sources, properties and applications-a review.Int. J. Food Sci. Technol. 44, 2512-2518.

FAOSTAT, 2015. Food and Agriculture Organization of the United Nations. FAO StatisticDivision.

Gao, H., Shupe, T.F., Eberhardt, T.L., Hse, C.Y., 2007. Antioxidant activity of extractsfrom the wood and bark of Port Orford cedar. J. Wood Sci. 53, 147.

Ghitescu, R.-E., Volf, I., Carausu, C., Bühlmann, A.-M., Gilca, I.A., Popa, V.I., 2015.Optimization of ultrasound-assisted extraction of polyphenols from spruce woodbark. Ultrason. Sonochem. 22, 535-541.

Hofmann, T., Nebehaj, E., Albert, L., 2015. The high-performance liquidchromatography/multistage electrospray mass spectrometric investigation andextraction optimization of beech (Fagus sylvatica L.) bark polyphenols. J.Chromatogr. A 1393, 96-105.

Kähkönen, M.P., Hopia, A.I., Vuorela, H.J., Rauha, J.-P., Pihlaja, K., Kujala, T.S.,Heinonen, M., 1999. Antioxidant activity of plant extracts containing phenoliccompounds. J. Agric. Food Chem. 47, 3954-3962.

Kammerer, D.R., Kammerer, J., Valet, R., Carle, R., 2014. Recovery of polyphenols fromthe by-products of plant food processing and application as valuable food ingredients. Food Res. Int. 65, 2-12.

Khoddami, A., Wilkes, M., Roberts, T., 2013. Techniques for analysis of plant phenoliccompounds. Molecules 18, 2328-2375.

Ku, C.S., Jang, J.P., Mun, S.P., 2007. Exploitation of polyphenol-rich pine barks for potentantioxidant activity. J. Wood Sci. 53, 524-528.

Lamounier, K.C., Cunha, L.C.S., de Morais, S.A.L., de Aquino, F.J.T., Chang, R., doNascimento, E.A., de Souza, M.G.M., Martins, C.H.G., Cunha, W.R., 2012. Chemicalanalysis and study of phenolics, antioxidant activity, and antibacterial effect of thewood and bark of Maclura tinctoria (L.) D. Don ex Steud. Altern. Med. 7. 
Lazar, L., Talmaciu, A.I., Volf, I., Popa, V.I., 2016. Kinetic modeling of the ultrasoundassisted extraction of polyphenols from Picea abies bark. Ultrason. Sonochem. 32,191197.

Liaudanskas, M., Viškelis, P., Raudonis, R., Kviklys, D., Uselis, N., Janulis, V., 2014.Phenolic composition and antioxidant activity of Malus domestica leaves. Sci. WorldJ.2014, 10.

Liazid, A., Palma, M., Brigui, J., Barroso, C.G., 2007. Investigation on phenoliccompounds stability during microwave-assisted extraction. J. Chromatogr. A 1140,29-34

.Mellouk, H., Meullemiestre, A., Maache-Rezzoug, Z., Bejjani, B., Dani, A., Rezzoug, S.A.,2015. Valorization of industrial wastes from French maritime pine bark by solventfree microwave extraction of volatiles. J. Clean. Prod. 1-8.

Mendes, M., Carvalho, A.P., Magalhães, J.M.C.S., Moreira, M., Guido, L., Gomes, A.M.,Delerue-Matos, C., 2016. Response surface evaluation of microwaveassistedextraction conditions for Lycium barbarum bioactive compounds. Innov. Food Sci.Emerg. Technol. 33, 319-326.

Montgomery, D.C., 1991. Design and Analysis of Experiments, third ed. Wiley, New York.

Morais, S., 2013. 18-Ultrasonic- and Microwave-assisted Extraction and Modification ofAlgal Components A2-Domínguez, Herminia, Functional Ingredients from Algae forFoods and Nutraceuticals. Woodhead Publishingpp. 585-605.

Moreira, M.M., Morais, S., Barros, A.A., Delerue-Matos, C., Guido, L.F., 2012. A novelapplication of microwave-assisted extraction of polyphenols from brewer's spentgrain with HPLC-DAD-MS analysis. Anal. Bioanal. Chem. 403, 1019-1029.

Muñiz-Márquez, D.B., Martínez-Ávila, G.C., Wong-Paz, J.E., Belmares-Cerda, R.,Rodríguez-Herrera, R., Aguilar, C.N., 2013. Ultrasound-assisted extraction ofphenolic compounds from Laurus nobilis L. and their antioxidant activity. Ultrason.Sonochem. 20, 1149-1154.

Naima, R., Oumam, M., Hannache, H., Sesbou, A., Charrier, B., Pizzi, A., -El, Charrier,Bouhtoury, F., 2015. Comparison of the impact of different extraction methods 
onpolyphenols yields and tannins extracted from Moroccan Acacia mollissima barks. Ind. Crops Prod. 70, 245-252.

Paíga, P., Morais, S., Oliva-Teles, T., Correia, M., Delerue-Matos, C., Sousa, A.M.,Gonçalves, M., Duarte, S., Pena, A., Lino, C., 2013. Determination of cchratoxin A inbread: evaluation of microwave-assisted extraction using an orthogonal compositedesign coupled with response surface methodology. Food Bioprocess Technol. 6,2466-2477.

Paz, M., Gúllon, P., Barroso, M.F., Carvalho, A.P., Domingues, V.F., Gomes, A.M., Becker,H., Longhinotti, E., Delerue-Matos, C., 2015. Brazilian fruit pulps as functional foodsand additives: evaluation of bioactive compounds. Food Chem. 172, 462-468

.Rana, S., Kumar, S., Rana, A., Sharma, V., Katoch, P., Padwad, Y., Bhushan, S., 2016.Phenolic constituents from apple tree leaves and their in vitro biological activity. Ind.Crops Prod. 90, 118-125.

Rubilar, M., Pinelo, M., Shene, C., Sineiro, J., Nuñez, M.J., 2007. Separation and HPLCMS identification of phenolic antioxidants from agricultural residues: almond hullsand grape pomace. J. Agric. Food Chem. 55, 10101-10109.

Stevanovic, T., Diouf, P.N., Garcia-Perez, M.E., 2009. Bioactive polyphenols from healthydiets and forest biomass. Curr. Nutr. Food Sci. 5, 264-295.

Tsubaki, S., Sakamoto, M., Azuma, J.-i., 2010. Microwave-assisted extraction of phenoliccompounds from tea residues under autohydrolytic conditions. Food Chem. $123,1255-1258$.

Walia, M., Kumar, S., Agnihotri, V.K., 2016. UPLC-PDA quantification of chemicalconstituents of two different varieties (golden and royal) of apple leaves and theirantioxidant activity. J. Sci. Food Agric. 96, 1440-1450

.Xü,K., Lü, H., Qü, B., Shan, H., Song, J., 2010. High-speed countercurrentchromatography preparative separation and purification of phloretin from apple treebark. Sep. Purif. Technol. 72, 406-409.

Yang, L., Jiang, J.-G., Li, W.-F., Chen, J., Wang, D.-Y., Zhu, L., 2009. Optimum extractionProcess of polyphenols from the bark of Phyllanthus emblica $L$ based on the responsesurface methodology. J. Sep. Sci. 32, 1437-1444. 
Zhang, B., Cai, J., Duan, C.-Q., Reeves, M., He, F., 2015. A review of polyphenolics in oakwoods. Int. J. Mol. Sci. 16, 6978.M.M. Moreira et al.Industrial Crops \& Products 104 (2017) 210-220220 